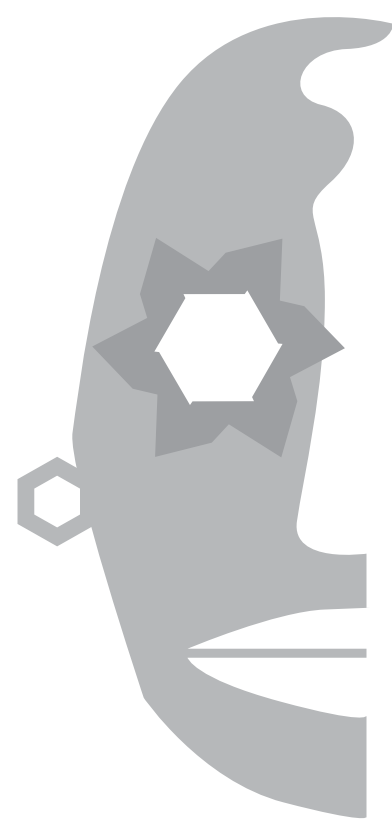

Rosa Sarabia
University of Toronto

\section{De la insularidad a la continentalización: el neopolicial cubano de Leonardo Padura}

\section{Resumen}

Este estudio se centra en el recorrido y desarrollo de Mario Conde, detective protagonista de las ocho novelas policiales del escritor cubano Leonardo Padura. De la tetralogía que se inicia con Pasado Perfecto, en 1991, hasta la ambiciosa y última entrega de Herejes, en 2013, Conde actúa mayormente dentro del "período especial" cubano marcado por la debacle de la Unión Soviética, para arribar a la primera década del siglo XXI. Dicho "período especial" produjo un quiebre en el desarrollo del género policial en Cuba. Por lo tanto, el género policial revolucionario, con apoyo oficial que nace a comienzos de la década de los 70, se transforma en los 90 para insertarse en la vertiente neopolicial que el resto de Latinoamérica venía desarrollando desde una década antes.

Lejos de los personajes modélicos revolucionarios del género en su origen, el neopolicial de Padura crea personajes que resuelven crímenes y delitos pero a la vez delinquen y evaden la ley. A partir de los casos que investiga, Conde se mueve dentro de esa paradójica conducta, al mismo tiempo que deconstruye y desmitifica las grandes políticas y discursos revolucionarios.

Palabras clave: Novela, Caribe, revolución, transformación social

\section{Abstract}

This study looks at the story and character development of detective Mario Conde, protagonist of Cuban author Leonardo Padura's eight crime novels. In the tetralogy that begins with Pasado Perfecto in 1991 and ends with the ambitious last installment entitled Herejes in 2013, Conde acts mostly during what is known as the Cuban "Special Period," marked by the fall of the Soviet Union, to later land in the first decade of the 21 st century. This "Special Period" produced a fracturing of crime fiction in Cuba and, as a result, the 
officially-supported revolutionary crime fiction that was born in the early 1970s later transformed in the 1990s to become part of the neo-crime genre that the rest of Latin America had been producing since a decade before.

Far from the exemplary revolutionary characters of the original genre, Padura's neo-crime characters not only solve crimes, but also commit them themselves and evade the law. Based on the cases he investigates, Conde moves within this paradoxical behavior while he deconstructs and demystifies the greatest revolutionary discourses and policies.

Keywords: Novel, Caribbean, revolution, social transformation

Dentro de las tendencias de la ficción detectivesca, policial o negra, el caso de Cuba es excepcional por tratarse de un género "revolucionario" que durante casi dos décadas tuvo orientación edificante, ofició de salvaguarda de la ideología marxista y estuvo al servicio de las políticas del sistema. De casi inexistente producción nacional anterior a la Revolución, en 1971 el género policial despegó con el apoyo oficial, instituyéndose en 1972 el premio "Concurso Aniversario del Triunfo de la Revolución," auspiciado y avalado por el Ministerio del Interior (MININT) ${ }^{1}$. Se dio, así, un movimiento involutivo en que el policial cubano se centró en el enigma y en el proceso de investigación, rasgos, entre otros, de la ficción detectivesca clásica. Por otro lado, el lugar del detective fue substituido por un cuerpo policial que, en colaboración con los comités de defensa de la revolución (CDR), se dio en combatir al delincuente/criminal que suponía una amenaza al proceso revolucionario.

Paradójicamente, el género duro (o negro), iniciado principalmente por Dashiell Hammett y Raymond Chandler y el que, según Ricardo Piglia, narra lo que el clásico detectivesco censura y excluye, o sea la crítica social (Piglia, 1992: 56), tuvo poca incidencia dentro de la práctica socialista. Cuando el género oficial se quiebra a comienzos de los noventa, da un salto cualitativo y vertiginoso, insertándose dentro de la vertiente neopolicial latinoamericana que venía trabajando desde finales de los años setenta y ochenta, precisamente con las sucesivas crisis del sistema capitalista, la desconfianza en la ley y la corrupción de sus gobiernos. La denuncia dirigida a la criminalidad del estado es la variante latinoamericana que se suma a la heredada conciencia crítica del género duro americano. Paco Taibo II define el neopolicial como la gran novela social del fin del milenio, formidable vehículo narrativo que "nos ha permitido poner en crisis las apariencias de las sociedades en que vivimos [...] por su intermedio entramos de lleno en la violencia interna de un Estado promotor de la ilegalidad y del crimen". (En Scantlenbory, 2000).

1 Stephen Wilkinson, entre otros críticos, admite la pobreza en materia detectivesca antes de la Revolución. En cambio, sí hubo una presencia mayor en la radio y cine durante la primera mitad del siglo XX.Enigma para un domingo (1971), de Ignacio Cárdenas, Acuña suele citarse como el que da inicio a este género en la Cuba postrevolucionaria. Ver el trabajo de Amelia Simpson para un mayor análisis sobre el tema. 
Con la fundación de la Semana negra en Gijón por el propio Paco Taibo II en 1988, el policial cubano salió de la isla y entró en amplio diálogo y debate con sus pares. Este intercambio coincidió con una relajación o debilitamiento de las políticas culturales de Cuba bajo "el periodo especial". Padura Fuentes así lo testimonia:

La crisis de los años noventa [...] trajo un gran espacio de libertad, pues no sólo hubo crisis económica, sino transformaciones sociales y espirituales muy profundas y una buena parte de ese miedo que persiguió a Iván [personaje de El hombre que amaba a los perros] desapareció, junto con la comida, el dinero, la electricidad, el papel, los ómnibus, los cigarrillos... Desde esa nueva perspectiva es que comenzamos a escribir en los noventa y es desde la que todavía hoy escribimos, con la posibilidad de editar nuestros libros fuera de Cuba, con una visión más crítica y hasta desencantada de la realidad, incluso con más apoyo de las instituciones culturales. Por todo eso, si en los ochenta casi todos escribíamos más o menos de los mismos temas y publicábamos en las mismas editoriales, hoy la literatura cubana es más diversa, está más descentrada geográficamente, es infinitamente más libre. (Entrevista con Fernando Bogado, 2010, s/n).

Un caso poco conocido aunque paradigmático de este cambio dentro de la isla, fue la doble versión y edición de Primero muerto..., novela escrita por Daniel Chavarría y Justo Vasco. La novela obtuvo en 1983 el premio del Concurso Aniversario del Triunfo de la Revolución, y fue publicada en 1986 por la editorial Letras Cubanas. Esta primera edición de enfoque didáctico y tratamiento laudatorio de las fuerzas revolucionarias tuvo una segunda edición en 1994, publicada en Uruguay. El cambio de una a otra edición no solo fue de orden ético, sino también estético. Los autores rebobinaron la trama; resucitaron al delincuente condenado a muerte, e hicieron desaparecer a la policía dejando una serie de crímenes sin resolución final. ${ }^{2}$

Según Whitfield, durante "el período especial" creció la publicación y publicidad de la ficción cubana, a punto tal que se habla del "nuevo boom cubano" con la obtención de una serie de premios, principalmente en España (Whitfield, 2008: 10). En este sentido, la literatura cubana se asimiló al resto de Latinoamérica, en cuanto a su dependencia de divisas extranjeras y de la industria del libro español. Desde ese momento se continentalizó la literal y metafórica insularidad del género.

Dentro de esta nueva corriente cubana se destacan Daniel Chavarría, Justo Vasco, José Latour, Amir Valle, Pedro Juan Gutiérrez, Lorenzo Lunar, Leonelo Abello Mesa, Rebeca Murga, María del Carmen Muzio y Leonardo Padura. La

2 Más acorde con la realidad cubana, la contratapa de la edición uruguaya califica la novela como "una descarnada reflexión sobre las diferentes formas de marginalidad que la revolución no logró transformar". Para un análisis mayor, ver Rosa Sarabia, "Primero muerto...Una novela bifronte: de revolucionaria a neo-policial." 
producción de este último cuenta con ocho títulos que van de Pasado Perfecto de 1991 a Herejes de 2013. Mario Conde, detective y protagonista de la serie, actúa cubriendo el período que va desde el derribo del muro de Berlín, pasando por la debacle de la Unión Soviética hasta el presente. Según el mismo Padura, Mario Conde es un tipo políticamente muy incorrecto para la ortodoxia cubana. No responde al detective como figura defensora, restauradora del orden y ejecutor de la ley sino a la voz que cuestiona y expone las contradicciones, abusos y corrupciones del sistema socialista. Sus rasgos principales se fundan en el escepticismo, la ironía y el cinismo, y su oficio va sufriendo cambios que semejan a los de su país. Lejos de los personajes modélicos revolucionarios del género en su origen, el neopolicial de Padura crea personajes que resuelven crímenes y delitos, pero a la vez delinquen y evaden la ley. En esa paradójica conducta se construye la desmitificación de las grandes políticas y discursos y revolucionarios. Paradójica también es la situación de Padura como escritor e intelectual, quien no habiendo nunca dejado Cuba fue uno de los primeros en publicar sus novelas en el exterior (México y España) con el acuerdo de que luego fueran editadas en Cuba para consumo interno. ${ }^{3}$

A excepción de Herejes, que relata el trágico evento histórico en que Cuba negó en 1939 el desembarco de 930 judíos que partieron de la Alemania nazi en el transatlántico SS Saint Louis, Padura arma sus novelas negras alrededor de la cambiante realidad de la isla a partir de 1989, significativa fecha en la que transcurre la tetralogía que abre la serie de Mario Conde (Pasado Perfecto, 1991, Vientos de cuaresma, 1994, Máscaras, 1997 y Paisaje de otoño, 1998). De un realismo más humano y social (que socialista), el neopolicial de Padura transforma el modelo maniqueísta del policial revolucionario en camaleónico, a tal punto que su última y más ambiciosa entrega, Herejes, cruza géneros y abandona algunas fórmulas del policial para decir otras cosas.

Al enmarcar la mayor parte de la serie entre 1989 y 2009 -con la salvedad de Herejes, que da un salto al siglo XVII holandés- los casos a los que debe enfrentarse Conde se van insertando en un contexto mayor de dominio público e internacional, como fueron el impacto que tuvo el "proceso de rectificación" de 1986 con un debate sobre la cultura y la homosexualidad, entre otros asuntos; la caída del muro de Berlín; el juicio y ejecución del General Arnaldo Ochoa Sánchez y otros tres militares en 1989; la debacle de la URSS; la inversión extranjera en el turismo, con el consiguiente aumento del mercado negro y de la prostitución; la posterior despenalización del dólar en 1993 que llevó, entre otras cosas, a que los

3 Padura cuenta con más de veinte prestigiosos premios y menciones nacionales e internacionales, entre los que vale la pena mencionar los más recientes: el Premio Nacional de Literatura (Cuba, 2012), la Orden de las Artes y las Letras (Francia, 2013) y el Premio Princesa de Asturias de las Letras (España, 2015). 
artistas pudieran negociar contratos en el exterior; las reformas de orientación capitalista con la autorización a la pequeña empresa, el empleo por cuenta propia y, más recientemente, la vuelta a la propiedad privada y a la inversión de capital extranjero a partir de asumir Raúl Castro la presidencia en 2008. Este contexto se convierte en subtexto de las narrativas, pero también da cuenta del proceso de escritura de un Leonardo Padura, que crea a un Mario Conde coetáneo y, por tanto, ambos hijos de la Revolución. Conde los llama "generación escondida," aquella que escuchaba música de los Beatles y de Creedence Clearwater Revival, aquella que no supo decir que no, aquella a la que "históricamente [les] tocaba obedecer" (Paisaje de otoño, 10).

Las siguientes páginas de este trabajo se centran en la transformación que sufre Mario Conde y el modo en que se resuelve - o no- la contradicción intrínseca del género negro, que se resume en un realismo de denuncia a la corrupción social al tiempo que requiere una resolución idealista en pos de una justicia final. En otras palabras, después de abrazar supuestamente la pasión de lo real que tiene un origen antagonista violento, el género negro propone el poder del simulacro en su fin utópico, según subraya Bruno Bosteels a partir de su lectura de "Filosofía de la serie negra" de Giles Deleuze (Bosteels, 2012: 264-65).

La "muerte del detective" es la metáfora que usa el crítico Glen Close para dar cuenta de una de las fracturas que el género sufre en Latinoamérica. A la posición tambaleante o fallida del detective, se nos provee una mayor visión aleccionadora del mundo social actual en que la objetivización capitalista y consumista, y la violencia cotidiana desafían la contención ideológica formulista que posee el género. A raíz de esta relación indirecta, Close señala que se produce el ascendiente criminal en la narrativa negra, y el detective se ve desplazado y reemplazado por un periodista o escritor o simplemente borrado, perdiéndose así todo agente mediador y, con ello, el residuo quijotesco con el que trabaja una línea del neopolicial (Close, 2006: 154). El Conde de Padura no llega a desaparecer como detective; sin embargo, a medida que avanza en la serie se convierte en uno sui generis, al adquirir otros oficios que le permiten incursionar, reflexionar y exponer la realidad cambiante de la isla.

Si bien la realidad cubana se ha abierto a una economía mixta (a lo que ya se hizo mención), no comparte el total desarrollo de capitalismo ni la violencia extrema de algunas regiones latinoamericanas. No obstante, con el aumento de la delincuencia y criminalidad a partir de "el periodo especial," La Habana en la que se mueve Mario Conde es un espacio que funciona como cartografía ideológica que

4 Algunos de estos ejemplos son: Novela negra con argentinos, de Luisa Valenzuela; "La loca y el relato del crimen" y Blanco nocturno, de Ricardo Piglia; "La nota roja que no existió", de Myriam Laurini; Los impostores, de Santiago Gamboa, y Tinta roja, de Alberto Fuguet, 
retiene, identifica y conecta la memoria del pasado con las ruinas y miserias del presente, según nota Rosi Song como aspecto general del género policial (Song, 2010: 464). Durante quince años, el teniente investigador Mario Conde recorre la ciudad interrogándola y juzgándola con sus prejuicios a cuestas. Como "cabrón recordador" arrastra nostalgia y escepticismo, mientras bebe y fuma a la manera del mejor detective duro. No tiene vocación de policía, aunque sí de escritor, pero justifica su oficio para que "los hijos de puta" no queden impunes, revelando ese fin justiciero que corona el género. Los casos que investiga involucran a viejos y jóvenes revolucionarios que, detentando posiciones de autoridad y privilegio, traman negocios ilegales, abusan de sus influencias, transgreden las leyes o tejen tramas corruptas.

En Máscaras, Conde revela su prejuicio homofóbico al hacerse cargo del asesinato del homosexual Alexis Arayán, hijo único de un diplomático y representante de Unicef que había fraguado documentos que le otorgaban un pasado revolucionario y clandestino contra Batista. La transformación de Conde pasa, de ser un "machista estalinista", a comprender humana e intelectualmente la figura marginada y defenestrada del dramaturgo Alberto Marqués -alter ego de Virgilio Piñera- quien fuera víctima del parametraje de los años setenta, cuando la homosexualidad constituía una diferencia ideológica y no de género. ${ }^{5}$ Se trata de una conversión hacia la heterodoxia: Conde participa del sistema de vigilancia al mismo tiempo que se ve vigilado.

Con la última entrega de la tetralogía, Conde se jubila de teniente policía con treinta y seis años para dedicarse a escribir. Aunque ya se había anticipado en el final de Vientos de cuaresma (segunda estación) que Conde algún día escribiría una crónica de odio y amor, felicidad y frustración que se titularía Pasado Perfecto (primera estación), ello se confirma en el final de la última y cuarta estación (Paisaje de otoño). He aquí un guiño anacrónico, o Conde reescribiendo la obra de Padura. Sin embargo, cierto es que la ficción se vuelve hacia sí misma y la figura del detective va cediendo a la de escritor, quien a partir de jubilarse realizará nuevas investigaciones, sea por pura curiosidad o por encargo, pero siempre desenmascarando el sistema desde dentro. "Detective por cuenta propia" se autoproclama a tono con una de las "correcciones necesarias" del gobierno de Raúl Castro.

Ya fuera del sistema de vigilancia y poder, Conde se dedica a la venta de libros en el mercado negro para poder sobrevivir, oficio que acompaña a la de escritor en Adiós, Hemingway (2001). Sin embargo, sigue prestando su pericia a la policía a

5 Durante "el período especial" se llevó a cabo una restitución póstuma, tanto de Virgilio Piñera como de Lezama Lima en el canon de la literatura cubana. Sobre la figura de Marqués como Piñera, ver la entrevista de Epple a Padura (1995: 58). 
través de su compañero Manuel, cosa que lo mantiene conectado a la investigación. A diferencia de Marlowe, moralista intachable y de una sola pieza, Conde expone las paradojas de su nuevo estado: "[...] era la caricatura de un cabrón detective privado en un país sin detectives ni privados, o sea, una mala metáfora de una extraña realidad [...] Por eso la posibilidad siempre latente de no llegar nunca a la verdad ni siquiera le molestaba" (106-107). Se produce, así, una doble desviación del género, tanto revolucionario como burgués: se sale de la construcción heroica del policía y se somete a la cadena económica, a una realidad materialista que, según Piglia, caracteriza a la serie negra (Piglia, 2001: 61). Sin embargo, no siempre Conde busca remuneración cuando actúa como detective, ambivalencia que le permite una vez más transgredir el modelo, como veremos más adelante.

En La neblina del ayer, su doble oficio de detective-librero pasa por transformaciones que afectan el carácter del personaje. Por un lado, aumenta su mirada crítica hacia el cuerpo policial por su corrupción, y lo hace en condición de sospechoso por el homicidio de un propietario de la biblioteca cuyos ejemplares Conde y Yoyi, el Palomo, su socio capitalista, intentan comprar. La vulnerabilidad de Conde se refuerza al ser víctima de una agresión física cuyos perpetradores nunca llega a descubrir; esta tendencia de dejar casos inconclusos o fallidos que de forma voluntaria accede a investigar es otro de los rasgos que caracterizan a Conde y al relato que de él Padura va construyendo. La agencia de Conde sigue siendo la verdad, pero no la que descansa en la resolución de un crimen, sino la que acompaña en denunciar la catástrofe social de un sistema que falla en proteger a su población.

Por otro lado, la posición ética de Conde se debilita a medida que cobra legalidad y beneficio la sociedad con los libros. En La neblina del ayer, cuyos hechos transcurren durante el 2003, se nos informa que "Conde siempre enfrentaba un leve malestar cuando fungía como depredador de bibliotecas y, por principio, decidió no comprar ningún libro acuñado, que advirtiera su origen de objeto público" (166). Un lustro más tarde, en Herejes, Conde se despoja de tales tribulaciones morales y ya no distingue la rareza de un libro por su valor de patrimonio nacional, sino por las "jugosas ganancias" que le reditúa en el mercado (335). Abandona, pues, su responsabilidad social en parte porque no la encuentra en la autoridad tutelar que debiera detentarla. Así, haciendo referencia a las asignaciones de casas expropiadas al comienzo de la revolución, apunta irónicamente: "aquel viejo dirigente político de los primeros tiempos de la Revolución, el cual (¡Quién lo diría!) estaba dispuesto a conversar sobre algunas joyas depositadas en su biblioteca revolucionariamente heredada". (337)

En todo caso, la tarea detectivesca de Conde va desdibujándose en Herejes. Anclada en eventos históricos, como se ha señalado, esta novela sacrifica algunas reglas del género, haciendo de este un instrumento o excusa para dar paso a una 
reflexión sobre el ser humano y su libertad, la que se ve restringida o anulada por dogmas políticos, ideológicos o religiosos. A partir de la llegada de un tal Elías Kaminsky a La Habana en 2007, Conde se ve envuelto en un par de casos relacionados entre sí, siendo una obra de arte de Rembrandt el elemento común y el hilo conector entre los tres libros que estructuran la novela. A cambio de un honorario de seiscientos dólares, Conde accede a ayudar en el rastreo de la pintura desde su ingreso a Cuba a bordo del SS Saint Louis en 1939. Sin embargo, los Kaminsky, portadores de la obra, corrieron diferente suerte y, rechazados, vuelven a Europa para terminar sus vidas en campos de concentración.

En dirección contraria a la situación económica impuesta en la isla a partir de los noventa, y a pesar de verse urgido por su situación financiera, que el negocio de los libros no logra resolver, Conde decide repartir el dinero ganado en partes iguales entre él y sus amigos. Revela de ese modo una suerte de solidaridad residual del proyecto socialista ínsita en la formación del personaje, gesto que se hace explícito en el tercer libro cuando dice haber aceptado el caso sobre la desaparición de Judy Torres, por "ayuda solidaria y desinteresada de su incontrolable curiosidad." (385)

Judy, joven "emo", lesbiana y virgen, es hija de un dirigente comunista que, además de dedicarse al contrabando de tecnología, es el último propietario de la obra de Rembrandt desaparecida y, a la vez, eslabón de una larga cadena de corrupción de oficiales gubernamentales de antes y después de la Revolución, que Conde se encarga de denunciar.

Los "emos", así como los "friquis", "punkys", "metaleros", "góticos", "repas" y "mikis", constituyen las llamadas tribus urbanas, cuyo individualismo contrasta con el espíritu solidario y colectivo del ideario revolucionario. Conde, a partir de recorrer "Emolandia" e instruirse en el tema con una doctora experta, resume así a los "emos": "[...] Judy y sus amigos resultaban la punta visible del iceberg de una generación de herejes con causa. Esos muchachos habían nacido y crecido sin nada, en un país que empezaba a alejarse de sí mismo [...] en el cual las viejas consignas sonaban cada día más huecas y desasidas, [...] la vida cotidiana se llenaba de nuevas exigencias: tener dólares, buscarse la vida por medios propios, no pretender participar de la cosa pública, mirar, como se observa un caramelo, el mundo que estaba más allá de las bardas insulares y aspirar a saltar hacia él." (442). En América Latina desigual y descentrada, Martín Hopenhayn explica la emergencia de estas nuevas identidades del siguiente modo: "Las tribus acuñan una moneda con dos caras: la de una exclusión que padecen sin querer y la de una identificación de excluidos que de maneras espasmódicas cuestionan el regimen de exclusiones" (Hopenhayn, 2005: 61). Conde expone y reflexiona la fractura del discurso revolucionario en que este va por un lado, y la realidad, por otro. La noción de "hombre nuevo" ya no encuentra cabida; en este sentido, al mismo tiempo que Herejes cubre relatos 
heterodoxos en defensa de la libertad de elección (como lo ha expresado Padura en varias entrevistas), es también un requiem por la Revolución.

Por otro lado, la vida personal y amorosa de Conde, quien tiene casi cincuenta y cinco años de edad, camina hacia el matrimonio, espacio vedado dentro de la tradición del género, ya que el coto solitario del detective supone un rechazo a toda forma de institución, incluido el matrimonio, según señala Piglia (2000: 67). De cumplirse esta transgresión en la próxima entrega de Padura, el propio Conde iría contra su espíritu libre, cínico y rebelde. Sin embargo, se podría leer esta decisión como una libertad respecto del género, exponiendo así su condición maleable de cambio de piel y cuestionando la validez de ciertas exigencias formularias.

Conde actúa como mediador e instrumento en los casos que investiga en Herejes, de ahí que la resolución de estos esté fuera de su alcance y propósito. La balanza se inclina hacia su vocación de escritor y, siendo que su primer cuento en la escuela secundaria fue censurado, le atraen aquellos relatos en los que la libertad de elección constituye la principal razón de ser en este mundo.

Ante la desconfianza en el sistema y el poder, el neopolicial cubano se hace consonante con el del resto de Latinoamérica, en que tanto las generaciones "escondidas" como las tribus urbanas han quedado huérfanos de proyectos colectivos y revolucionarios. "Solo vale la pena militar en la tribu que tú mismo has elegido libremente [...] lo único que te queda, lo único que en realidad te pertenece, es tu libertad de elección" (513), concluye Conde en su última herejía.

\section{Referencias}

Bogado, Fernando (16 de mayo de 2010). "El huracán de la historia." Entrevista. Radar Libros, suplemento literario Página/12, s/p. http://www.pagina12.com. ar/diario/suplementos/libros/10-3834-2010-05-16.html

Bosteels, Bruno (2012). Marx and Freud in Latin America: Politics, Psychoanalysis, and Religion in Times of Terror. London and New York: Verso.

Chavarría, Daniel y Justo E. Vasco(1986). Primero muerto... La Habana: Letras cubanas. . (1994). Primero muerto... Montevideo: Graffiti y Cal y Canto.

Close, Glen S. (2006). "The Detective is Dead Long Live the Novela negra!. Hispanic and Luso-Brazilian Detective Fiction. Renée Craig-Odders, Jacky Collins \& Glen S. Close (Eds). Jefferson, North Carolina, London: McFarland \& Company, 143-161.

Epple, Juan Armando (1995). "Entrevista a Leonardo Padura." Hispamérica: Revista de Literatura, 24.71, 49-66. 
Hopenhayn, Martín. (2005). América Latina desigual y descentrada. Buenos Aires: Ed. Norma.

Padura, Leonardo. (2000 [1991]). Pasado Perfecto. Barcelona: Tusquets. . (1994). Vientos de cuaresma. La Habana: Unión. . (2007 [1997]).Máscaras. Barcelona: Tusquets. . (1998).Paisaje de otoño. Barcelona: Tusquets. . (2006 [2001]).Adiós, Hemingway. México DF: Tusquets. . (2005).La neblina del ayer. Barcelona: Tusquets. . (2011).La cola de la serpiente. México DF: Tusquets, . (2013).Herejes. Barcelona: Tusquets.

Piglia, Ricardo. (1992). "Lo negro del policial.” En Daniel Link (editor). El juego de los cautos. La literatura policial: de Poe al caso Giubileo. Buenos Aires: La marca editora, 55-59. . (2000). "Los sujetos trágicos. Literatura y Psicoanálisis." Formas breves. Barcelona: Anagrama. . (2001). Crítica y ficción. Barcelona: Anagrama.

Sarabia, Rosa.(2011). "Primero muerto...Una novela bifronte: de revolucionaria a neo-policial," Pasajes: Revista de pensamiento contemporáneo, 35, (Spring), 105-112.

Scantlenbory, Marcia (2000) "Paco Ignacio Taibo II: La novela negra es la gran novela social de fin de milenio." Caras, s/p. www.cl.caras/ediciones/paco. htlm

Simpson, Amelia S. (1990). Detective Fiction from Latin America. London \& Toronto: Associated University Presses.

Song, H. Rosi (2010). “En torno al género negro: ¿La disolución de una conciencia ética o la recuperación de un nuevo compromiso político?". Revista Iberoamericana, Vol. LXXVI, (231), 459-475.

Whitfield, Esther (2008). Cuban Currency. The Dollar and "Special Period" Fiction. Minneapolis/London: University of Minnesota Press.

Wilkinson, Stephen. (2006). Detective Fiction in Cuban Society and Culture. Bern: Peter Lang. 